\title{
Evaluation of health services: A directive for public health professionals
}

\author{
Saurabh RamBihariLal Shrivastava ${ }^{a}$, Prateek Saurabh Shrivastavab, Jegadeesh Ramasamyc \\ a Assist. Prof., Shri Sathya Sai Medical College \& Research Institute, Department of Community Medicine, \\ Kancheepuram, India \\ b Assist. Prof., Shri Sathya Sai Medical College \& Research Institute, Department of Community Medicine, \\ Kancheepuram, India \\ c Prof., Shri Sathya Sai Medical College \& Research Institute, Department of Community Medicine, \\ Kancheepuram, India
}

Submitted: 23.04.2014, Accepted: 16.10.2014

This letter provides information for the public health professionals and program managers to improve the reach of public health welfare strategies by ensuring effective evaluation of the existing services.

In the global mission to improve the quality of life of people and provide health care services to all, both developed and developing nations have implemented different welfare strategies based on the local needs. ${ }^{1}$ However, these health services are highly complex and concerns have been raised to assess the quality of medical care; utilization and coverage of health services; and benefits to community health in terms of morbidity/mortality reduction and improvement in the health status of the recipients of care. ${ }^{2}$ Thus, to address all these concerns, evaluation of health strategies/ policies has been recommended. ${ }^{2}$

Evaluation is the process of assessing the extent to which results is commensurate with the pre-decided objectives. ${ }^{3}$ It should be an ongoing process as the program progresses (concurrent evaluation) and not simply an exercise to be undertaken at the end of the program (terminal evaluation). ${ }^{2}$ In fact, evaluation has emerged as one of the most significant accountability tool in the current health setup and is a crucial dimension of decision making about the release of financial aid from policy makers in the subsequent year. 2,3

In order to ensure effective coordination between national and community-level evaluation efforts, the guidelines for performing an evaluation should be explicit and at the same time flexible enough to reflect the diversity of programmatic activities and people-specific health needs. ${ }^{4}$ Ideally the process of evaluation has to be systematically planned and should consist of the following steps, namely: identifying what has to be evaluated (viz.whether facilities/ equipment /manpower meet the desired standards; in what manner various activities in a program are performed; whether the beneficiaries of the health services have experienced benefits in terms of reduction in morbidity/ mortality/disability or improvement in satisfaction levels/life expectancy/quality of life; defining the standards and criteria to assess how well the desired objectives have been attained; formulating a methodology

Corresponding Author: Saurabh RamBihariLal Shrivastava, Shri Sathya Sai Medical College \& Research Institute, Kancheepuram, India; E-mail: drshrishri2008@gmail.com 
to conduct the evaluation; collection of the data; analysis and interpretation of data and giving feedback to all the involved stakeholders; implementation of corrective measures to support, strengthen or modify the services involved; and finally reevaluation to assess the results of the remedial steps. ${ }^{2,4,5}$

However, to be effective, the complete process of evaluation should explore six different facets of a program/health service such as:

a) relevance (refers to the appropriateness of the service, to indicate whether the service is needed at all),

b) adequacy (to indicate that sufficient attention has been paid to previously defined course of action),

c) accessibility (to estimate proportion of general population expected to avail the services of a specific welfare scheme),

d) acceptability (to assess whether the provided services are acceptable to the target population for whom services are planned),

e) effectiveness (viz. does it work in real life scenarios), and

f) efficiency (viz. is it the most economical way in terms of time or money).1,2,5

In fact, it has been proposed that a program evaluation should be considered right from the inception of any public health program (viz. in the planning stage). ${ }^{3}$ Furthermore, the process of evaluation should not only target health care providers and program managers but also explore the needs of patients/families/communities to simultaneously address their concerns and thus bring about significant improvement in health indicators. ${ }^{4,5}$

To conclude, evaluation of a health program or services is a continuous process done to assist public health professionals in ensuring modification of public health policies and in addressing the health concerns of the beneficiaries.

\section{References}

1. Aikins J, Lloyd L, Joyner I. A scan of program evaluation at the Houston department of health and human services. Public Health Rep 2007;122(5):707-711.

2. Park K. Health planning and management. In: Park K, editor. Text Book of Preventive and Social Medicine. 20th ed. Jabalpur: Banarsidas Bhanot Publishers; 2009. p. 784785.

3. Houston JM, Martin M, Williams JE, Hill RL. The Annual African American Conference on Diabetes: evolving program evaluation with evolving program implementation. Prev Chronic Dis 2006;3(1):A18.

4. Shadish WR. The common threads in program evaluation. Prev Chronic Dis 2006;3(1):A03.

5. Milstein RL, Wetterhall SF. Framework for program evaluation in public health. MMWR Recomm Rep 1999;48(RR-11):1-40. 